\title{
MODELOS DE ESTIMATIVA DE PRODUTIVIDADE POTENCIAL PARA AS CULTURAS DO FEIJÃO E DO MILHO
}

\author{
Leydimere Janny Cota Oliveira ${ }^{1}$, Luiz Cláudio Costa ${ }^{2}$, Gilberto Chohaku Sediyama ${ }^{3}$, Williams Pinto Marques \\ Ferreira $^{4}$, Marcelo Jorge de Oliveira ${ }^{5}$
}

\begin{abstract}
RESUMO
O clima tem significativo impacto no crescimento e desenvolvimento das culturas. Muitos modelos agrometeorológicos têm sido utilizados para quantificar estes impactos. Diante da importância da disponibilidade de modelos simples, capazes de considerar os efeitos de diversos fatores na produtividade potencial, ainda que os resultados dos modelos mais utilizados ainda não tenham sido comparados em condições tropicais, este trabalho foi desenvolvido com os seguintes objetivos: calcular e comparar a produtividade potencial das culturas do feijão e do milho em algumas mesorregiões do Estado de Minas Gerais. Para tanto, modelos baseados em processos, utilizando as equações de Blackman, hipérbole retangular, exponencial negativa, hipérbole não retangular e uso eficiente da radiação, como parte central no cálculo do balanço de carbono, foram utilizados para estimar a variabilidade da produtividade das culturas de milho e feijão, em algumas mesorregiões do Estado de Minas Gerais, a partir de dados diários meteorológicos históricos de 1975 a 2004. A diferença percentual entre o modelo de maior estimativa de produtividade e o de menor foi de $105 \%$ para a cultura do feijão e de $108 \%$ para a cultura do milho. A produtividade potencial, calculada por meio dos diferentes modelos, diferiu substancialmente, indicando que a escolha do modelo a ser usado deve ser feita de forma criteriosa.
\end{abstract}

Palavras-chave: Modelo agrometeorológico, balanço de carbono, estimativa de produtividade.

\section{MODELS TO ESTIMATE POTENTIAL YIELD OF BEANS AND MAIZE CROPS}

\begin{abstract}
Climate has significant impact on crop growth and development, and several agro-meteorological models have been used for its quantification. Considering the importance of simple models capable of considering effects of various factors on yield potential, and the absences of data regarding there application under tropical conditions, this work was done to calculate and compare the potential yield of bean and maize crops in the mesoregions of Minas Gerais State. Using daily meteorological data from 1975 to 2004, some process-based models such as Blackman's equation, the negative exponential, rectangular hyperbole, non-rectangular hyperbole, and the efficient radiation use, were used as the central part to calculate carbon balance in order to estimate yield variability of maize and bean crops. The percent difference between the model predicting highest and the lowest estimates was $105 \%$ for bean and $108 \%$ for maize crops. The potential yield estimated by these models differed significantly, indicating criteria based choice of the model to be used.
\end{abstract}

Keywords: Agrometeorological model, carbon balance, estimates of productivity.

\section{Recebido para publicação em 20/05/2010. Aprovado em 19/07/2010.}

1- Engenheira Ambiental, Doutoranda em Meteorologia Agrícola - Dep. de Engenharia Agrícola, UFV, Viçosa- MG, e-mail: leydimere.oliveira@ufv.br

2- Licenciado em Matemática, Professor Associado do Dep. de Engenharia Agrícola, UFV, Viçosa- MG, email: 1.costa@ufv.br

3- Engenheiro Agrônomo, Professor Titular do Dep. de Engenharia Agrícola, UFV, Viçosa- MG, email: g.sediyama@ufv.br

4- Meteorologista, Pesquisador da Empresa Brasileira de Pesquisa Agropecuária Milho e Sorgo, Sete Lagoas-MG, email: williams@ cnpms.embrapa.br.

5- Engenheiro Agrimensor, Professor Assistente do Dep. de Engenharia de Minas,UFG, Catalão-GO, email: msc.marcelo@yahoo.com.br

\section{REVENG}




\section{INTRODUÇÃO}

A interação entre as plantas e o ambiente envolve uma complexidade de processos físicos, químicos e biológicos. Visando a obter um conhecimento mais profundo sobre as respostas da cultura ao ambiente, modelos de simulação são utilizados como ferramentas de grande potencial na área de sistemas cultivados, pois possibilitam o estudo e o entendimento do conjunto, estimando o desempenho da cultura em diferentes localidades e situações (TOJO SOLER, 2004).

Vários modelos, a maioria com fundamentação estatística, vêm sendo desenvolvidos no sentido de definir a produtividade potencial das culturas (FAO, 2003). Todavia, considerando a não-linearidade e a complexidade da relação entre clima e cultura, modelos baseados em processos também vêm sendo utilizados para definir a produtividade potencial das culturas (EASTERLING et al., 2001; PARRY et al., 2004). Estes modelos comumente utilizam o balanço de carbono das culturas, tendo como variáveis de entrada, unicamente, a radiação e a temperatura, não considerando nenhuma outra restrição ambiental. O estudo dos impactos na produtividade potencial é ferramenta importante, pois não considera incertezas como restrição hídrica e nutricional, pragas e doenças, solo, entre outros.

Nos modelos baseados em processos desenvolvidos nos últimos anos cinco equações vêm sendo utilizadas como parte central no cálculo do balanço de carbono: Blackman, hipérbole retangular, exponencial negativa, hipérbole não retangular e o uso eficiente da radiação (CHAN, 1992). No entanto, é aceitável esperar que, devido às pressuposições básicas consideradas em seu desenvolvimento, estas equações apresentem diferenças em seus resultados.

Desta forma, considerando a importância da disponibilidade de modelos simples e confiáveis de estimativa da produtividade potencial e, além disso, que os resultados dos modelos mais utilizados ainda não tenham sido comparados em condições climáticas brasileiras, o objetivo deste trabalho foi calcular e comparar a produtividade potencial das culturas do feijão e do milho, para algumas mesorregiões do Estado de Minas Gerais, utilizando os modelos citados anteriormente.

\section{MATERIAL E MÉTODOS}

Dados meteorológicos diários de temperaturas do ar (máxima, mínima e média) e insolação de 19 estações, fornecidos pelo $5^{\circ}$ Distrito do Instituto Nacional de Meteorologia (INMET), representativas de sete mesorregiões do Estado de Minas Gerais, para uma série de 30 anos (1975 a 2004), foram utilizados no estudo. Para as simulações da cultura do feijão, foram utilizados dados da cultivar Pérola, grupo comercial carioca que apresenta ciclo de aproximadamente 90 dias. Para as simulações da cultura do milho, foram usados dados da cultivar AGN 2012 (Híbrido duplo), que apresenta ciclo de aproximadamente 116 dias. A data de semeadura foi 15 de outubro para todas as simulações.

Foi desenvolvido um modelo modular utilizando o software Model Maker 3.0 ${ }^{\circledR}$ CSPL (Cherwell Scientific Plublishing Limited). Tal modelo simulou a produção de matéria seca diária determinada pela intensidade de radiação e temperatura média. O modelo consistiu nos seguintes módulos: (a) climático, (b) radiação, (c) balanço de carbono e (d) desenvolvimento e partição de matéria seca.

Para o cálculo do balanço de carbono, foram utilizadas as equações de Blackman, exponencial negativa, hipérbole retangular, hipérbole não retangular e uso eficiente da radiação.

A curva de Blackman propõe uma resposta inicial linear à radiação (região limitada pela intensidade da luz), posteriormente o suprimento disponível de $\mathrm{CO}_{2}$ não permite aumentos na taxa fotossintética com aumentos na radiação (região limitada pela concentração de $\mathrm{CO}_{2}$ ), havendo, portanto, uma descontinuidade acentuada entre as regiões limitadas pela luz e pelo $\mathrm{CO}_{2}$, fazendo com que a transição para a saturação seja abrupta. A curva de Blackman é dada pela expressão (CHAN, 1992):

$$
F_{g}=F_{g \max } \min \left\{\begin{array}{c}
\frac{\varepsilon I}{F_{g \max }} \\
1
\end{array}\right.
$$


$\mathrm{Na}$ exponencial negativa, a resposta à luz tem um declive inicial mais íngreme, sendo a transição para a saturação feita de forma gradual comparada às demais curvas. A curva exponencial negativa é definida por (CHAN, 1992):

$$
F_{g}=F_{g \max }\left(1-\exp \left(-\frac{\varepsilon I}{F_{g \max }}\right)\right)
$$

A hipérbole retangular não apresenta descontinuidade, mas alcança a saturação muito lentamente e pode ser calculada por (CHAN, 1992):

$$
F_{g}=F_{g \max }\left(\frac{\varepsilon I}{F_{g \max }} /\left(1+\left(\frac{\varepsilon I}{F_{g \text { max }}}\right)\right)\right)
$$

$\mathrm{Na}$ hipérbole não-retangular, há outro parâmetro conhecido como parâmetro de forma, que varia entre 0 e 1 , sendo tal parâmetro definido como a razão da resistência de difusão de $\mathrm{CO}_{2}$ pela resistência total. A curva da hipérbole não retangular é descrita por (CHAN, 1992):

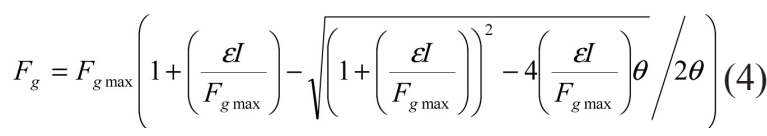

em que,

$F_{\text {gmax }}=$ taxa máxima de fotossíntese da cultura ( $\mathrm{g}$ $\mathrm{m}^{-2} \mathrm{dia}^{-1} \mathrm{de} \mathrm{CO}_{2}$ );

$\varepsilon=$ eficiência fotossintética $\left(\mathrm{g} \mathrm{MJ}^{-1}\right.$ de $\left.\mathrm{CO}_{2}\right)$;

$I=$ RFA interceptada pela cultura $\left(\mathrm{MJ} \mathrm{m}^{-2} \mathrm{dia}^{-1}\right)$;

$\theta=$ parâmetro de forma $(0-1)$; e

$F_{g}=$ taxa de fotossíntese bruta $\left(\mathrm{g} \mathrm{m}^{-2} \mathrm{dia}^{-1} \mathrm{de} \mathrm{CO}_{2}\right)$.

O método do uso eficiente da radiação proposto por Monteith (1977) permite estimar a produtividade de uma cultura considerando um único parâmetro, e se baseia na existência de uma relação linear entre o acúmulo de matéria seca total e a quantidade de radiação fotossinteticamente ativa interceptada pela cultura. Este método pode ser expresso da seguinte forma (MONTEITH, 1977):

$$
\frac{d M S}{d t}=U E R \times R F A
$$

em que,

$M S$ = quantidade de matéria seca produzida pelas plantas ( $\mathrm{g} \mathrm{m}^{-2}$ dia $^{-1}$ de MS);

$R F A=$ radiação fotossinteticamente ativa interceptada pela cultura $\left(\mathrm{MJ} \mathrm{m}^{-2} \mathrm{dia}^{-1}\right)$; e

$U E R=$ eficiência de conversão de RFA em matéria seca $\left(\right.$ g.MJ ${ }^{-1}$ de $\left.\mathrm{MS}\right)$.

Nos modelos utilizando as equações de Blackman, exponencial negativa, hipérbole retangular e hipérbole não retangular, o balanço diário de carbono foi definido como a matéria seca resultante da diferença entre a assimilação e a respiração de manutenção diária da cultura. Em seguida, o ganho de carbono simulado foi convertido em matéria seca, por meio da respiração de crescimento. E o acúmulo da matéria seca, ao longo do tempo, foi estimado conforme Penning de Vries (1975).

$$
\frac{d M S}{d t}=\left(F_{g}-R_{m} M S\right) r_{c}
$$

em que,

$r c$ = eficiência de conversão de carboidrato ( $\mathrm{g}$ de $\mathrm{CO}_{2}$ por $\mathrm{g} \mathrm{MS}$ );

$\mathrm{R}_{\mathrm{m}}=$ respiração de manutenção $\left(\mathrm{g} \mathrm{m}^{-2} \operatorname{dia}^{-1} \mathrm{de} \mathrm{CO} 2\right)$.

No último modelo, o acúmulo de matéria seca das culturas foi calculado por meio do uso eficiente da radiação proposto por Monteith (1977). Para todos os modelos, o processo fisiológico foi caracterizado através de dois parâmetros específicos para cada variedade: tempo térmico para o florescimento e para a maturação. E, à medida que se acumularam os totais de graus-dia exigidos pela cultura para a ocorrência dos eventos fenológicos, o módulo referente à partição de assimilados distribuiu a assimilação diária entre os órgãos da planta. O rendimento de grão foi estimado pela percentagem de matéria seca alocada para os órgãos reprodutivos em função da fase fenológica. A simulação foi concluída quando a 


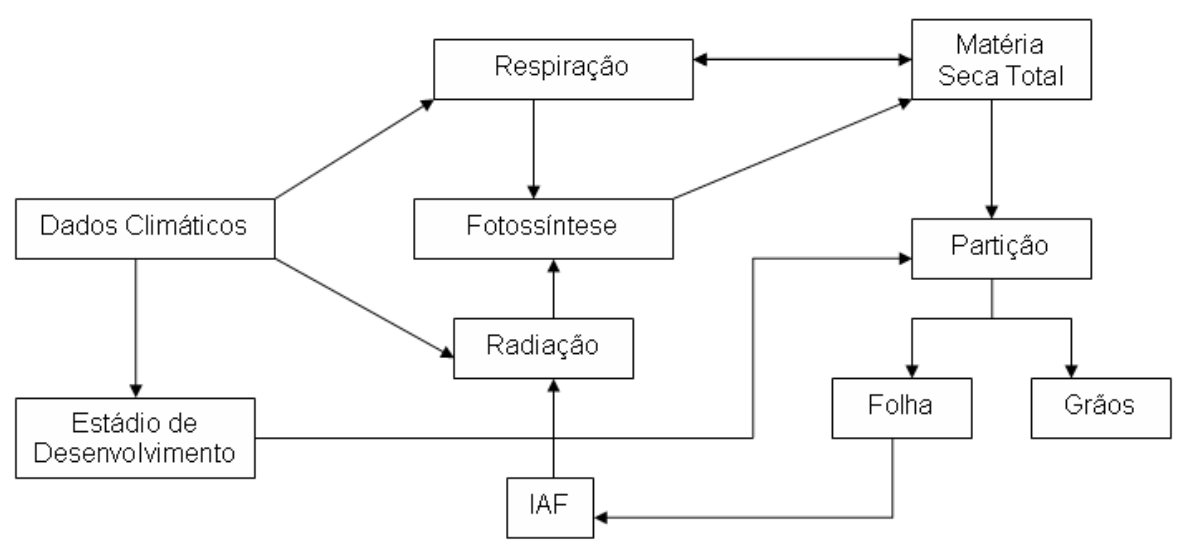

Figura 1. Fluxograma da inter-relação dos principais componentes do modelo

cultura atingiu a maturidade fisiológica. A estrutura básica do modelo desenvolvido é demonstrada no fluxograma apresentado na Figura 1.

\section{RESULTADOS E DISCUSSÃO}

As estimativas da produtividade potencial para a cultura do feijão pelos diferentes modelos, para as mesorregiões Zona da Mata e Vale do Jequitinhonha, são apresentadas nas Figuras $2 \mathrm{e}$, respectivamente, para fins de comparação. Também foram plotados valores de produtividade potencial para o cultivar Pérola, de acordo com Embrapa (2007) e Ministério da Agricultura (BRASIL, 2007a). Nas Figuras 4 e 5, estão representadas as estimativas da produtividade potencial para a cultura do milho, respectivamente, para as mesorregiões Zona da Mata e Vale do Jequitinhonha. Foi plotado também o potencial produtivo para o cultivar AGN 2012, de acordo com Ministério da Agricultura (BRASIL, 2007b) e experimento realizado por Wolschick (2004). Os resultados apresentados em todas as figuras foram obtidos no período de 1975 a 2004 . .

Nas Figuras 2 a 5, observa-se a variabilidade anual na produtividade potencial estimada, influenciada pelas diferentes condições climáticas ocorridas a cada ano. Vale ressaltar que as cinco metodologias apresentaram respostas similares às condições climáticas experimentadas para as duas culturas e ambas as mesorregiões do Estado. Tal comportamento já era esperado, pois as simulações do crescimento e do desenvolvimento das culturas em todos os modelos foram realizadas utilizando os mesmos dados climáticos.

Quanto à variabilidade anual da produtividade, destaca-se o ano de 1997, na mesorregião Vale do
Jequitinhonha (Figura 3), para a cultura do feijão. Para esse ano, o ciclo da cultura foi de 85 dias, apresentando, portanto, a menor produtividade em todos os modelos para esta mesorregião. Resultado similar foi observado na mesorregião Zona da Mata (Figura 4) em 1991 e 1992, anos em que foram observados os menores valores de produtividade potencial por todos os modelos para a cultura do milho, conseqüência também da diminuição do ciclo da cultura, respectivamente, de 108 dias e 112 dias. Na mesorregião Vale do Jequitinhonha (Figura 5), a menor produtividade para todos os modelos foi observada em 1977 e a maior em 2001 para a cultura do milho, sendo que os ciclos para os respectivos anos foram de 130 dias e 118 dias. Como o ciclo referente ao ano de 1977 foi muito superior ao padrão (116 dias), houve muita perda devido à respiração de manutenção, totalizando $53 \%$ da fotossíntese bruta, enquanto no ano de 2001 , essa perda foi de $50 \%$.

Os resultados evidenciam que as diferenças na produtividade potencial, estimadas por meio das cinco equações, foram amplas. Para as duas culturas, as estimativas da produtividade potencial pela curva de Blackman foram as maiores, seguida da hipérbole não retangular, da exponencial negativa e do uso eficiente da radiação, sucessivamente, sendo que as menores estimativas foram apresentadas pela hipérbole retangular.

Usando a produtividade potencial média obtida pela hipérbole não retangular, como base para comparação, as magnitudes das diferenças em termos percentuais foram da ordem de $47 \%,-20 \%,-28 \%$ e $-23 \%$ para a cultura do feijão e de $51 \%,-4 \%,-28 \%$ e $-16 \%$ para a cultura do milho, para o modelo de Blackman, a exponencial negativa, a hipérbole retangular e o uso eficiente da radiação, respectivamente. 


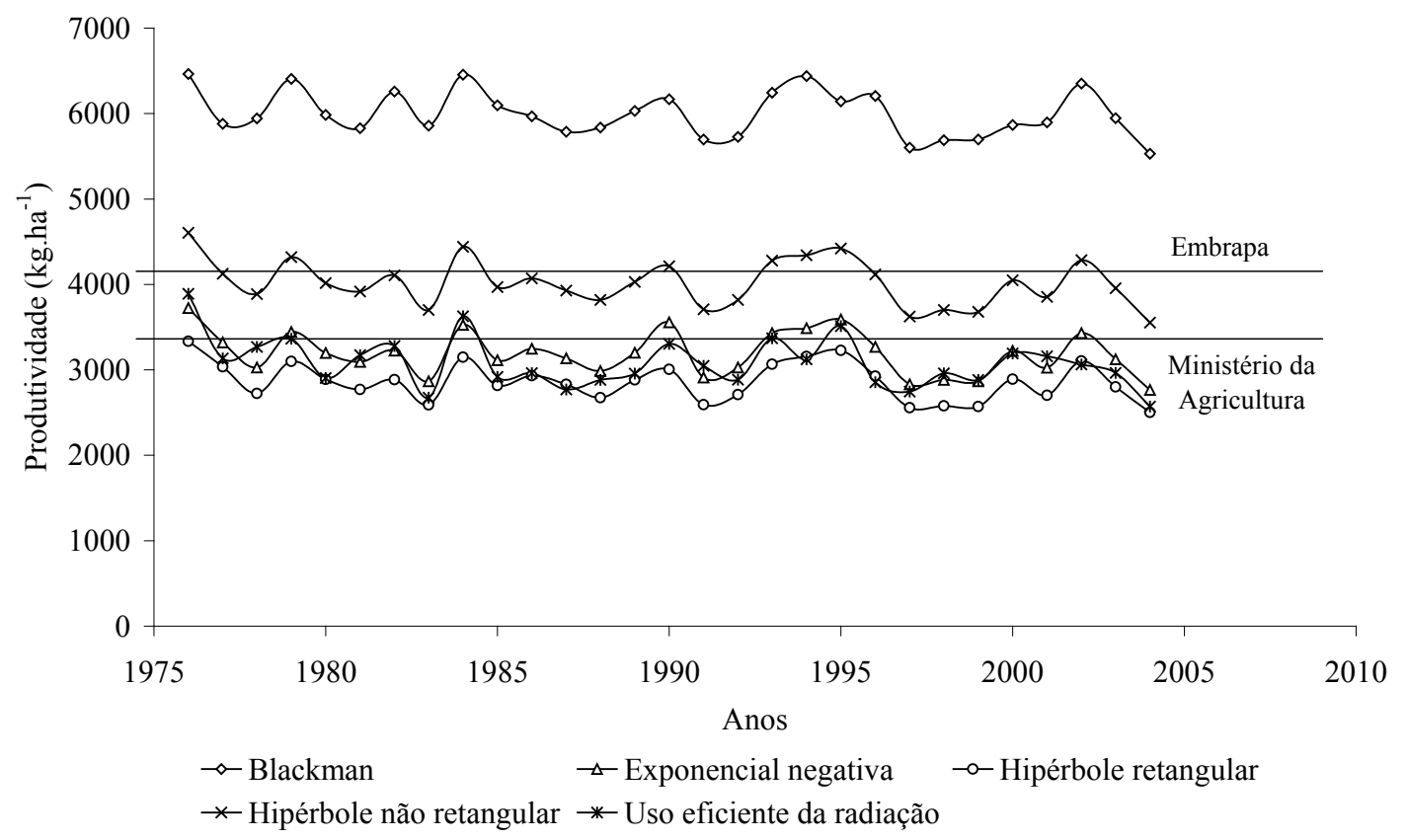

Figura 2. Produtividade potencial média do feijão $\left(\mathrm{kg} \cdot \mathrm{ha}^{-1}\right)$, simulada pelos cinco modelos para a mesorregião Zona da Mata, com semeadura em 15 de outubro e o potencial produtivo de acordo com Embrapa e Ministério da Agricultura.

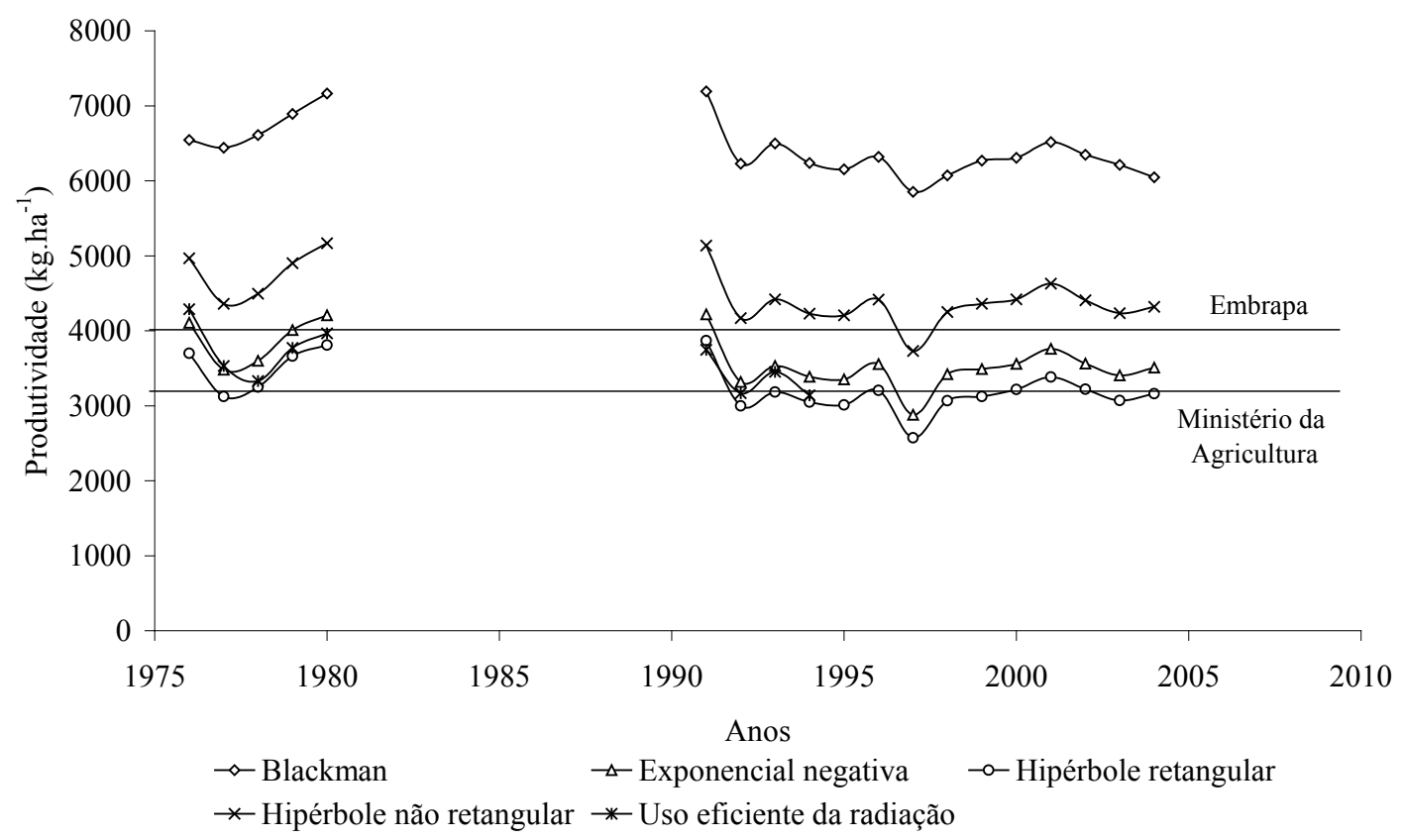

Figura 3. Produtividade potencial média do feijão $\left(\mathrm{kg} \cdot \mathrm{ha}^{-1}\right)$, simulada pelos cinco modelos para a mesorregião Vale do Jequitinhonha, com semeadura em 15 de outubro e o potencial produtivo de acordo com Embrapa e Ministério da Agricultura. 


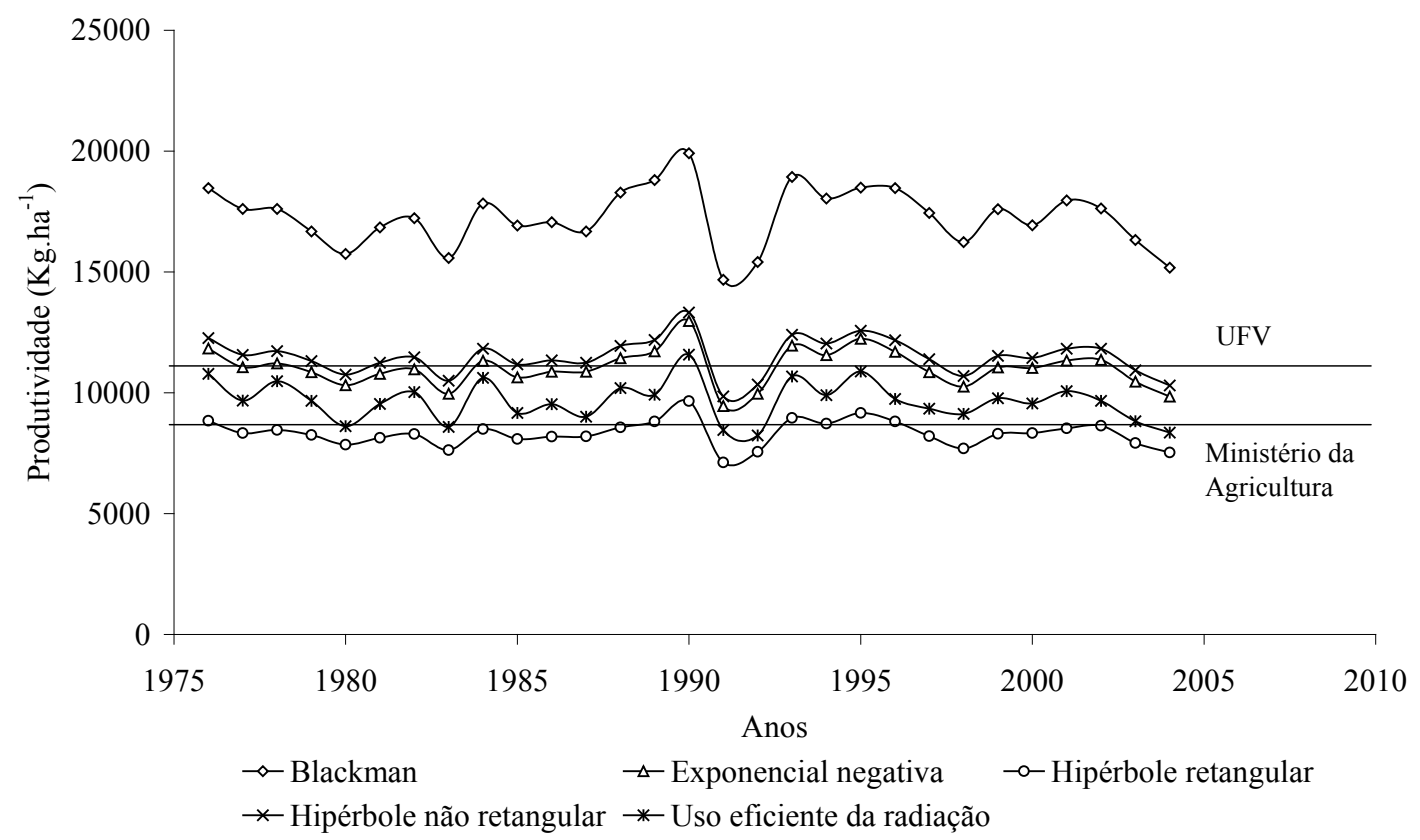

Figura 4. Produtividade potencial média do milho $\left(\mathrm{kg} \cdot \mathrm{ha}^{-1}\right)$, simulada pelos cinco modelos para a mesorregião Zona da Mata, com semeadura em 15 de outubro e o potencial produtivo de acordo com UFV e Ministério da Agricultura.

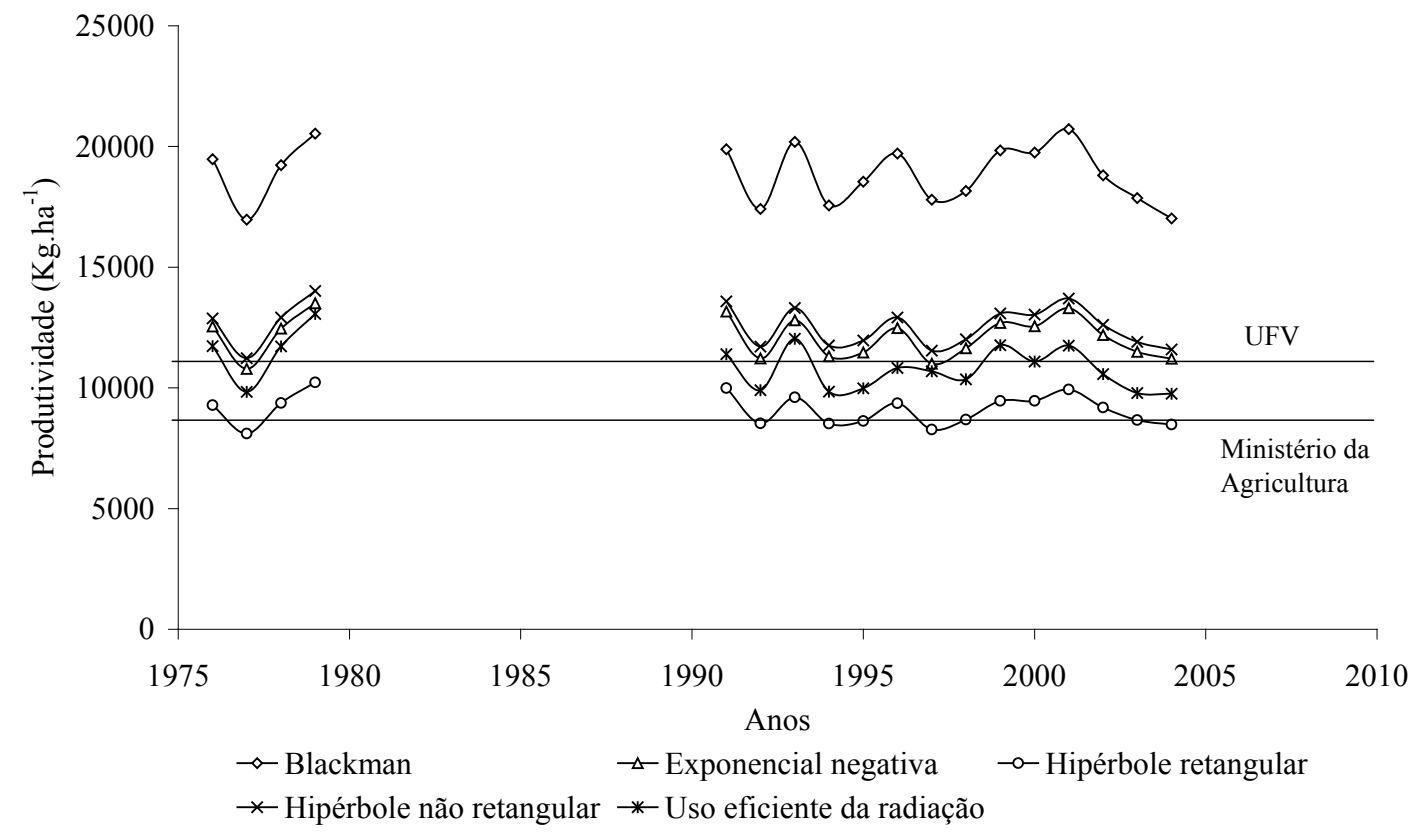

Figura 5. Produtividade potencial média do milho $\left(\mathrm{kg} \cdot \mathrm{ha}^{-1}\right)$, simulada pelos cinco modelos para a mesorregião Vale do Jequitinhonha, com semeadura em 15 de outubro e o potencial produtivo de acordo com UFV e Ministério da Agricultura. 
Nas simulações da produtividade potencial são notadas diferenças nos valores entre elas, Quadros 1 e 2, causadas, provavelmente, pelas diferentes condições climáticas de cada mesorregião. Para a cultura do feijão, a mesorregião Vale do Jequitinhonha apresentou os maiores valores de produtividade potencial média para todos os modelos, e a mesorregião Central Mineira, os menores. Para a cultura do milho, os maiores valores de produtividade potencial média para todos os modelos foram observados na mesorregião Campos das Vertentes, e os menores, na mesorregião Central Mineira. Tais desigualdades foram causadas, principalmente, pelas diferenças na temperatura do ar, uma vez que temperaturas mais altas têm, como conseqüência, menor assimilação de carbono pela planta, decorrente do encurtamento das fases fenológicas e aumento na taxa de respiração de manutenção.

No Quadro 3, encontram-se os desvios entre a produtividade potencial média estimada pelos cinco modelos e a produtividade potencial, obtida na literatura. De acordo com os valores dos desvios, a produtividade potencial estimada pelo modelo de Blackman foi muito superior aos valores obtidos na literatura para as duas culturas. Por outro lado, os modelos da exponencial negativa, da hipérbole retangular, da hipérbole não retangular e do uso eficiente da radiação apresentaram estimativas de produtividade potencial próximas aos valores obtidos na literatura.

O modelo do uso eficiente da radiação é o mais simples entre os modelos testados. O uso eficiente da radiação incorpora processos fisiológicos, que são sensíveis às condições ambientais e ao estado da cultura (GOUDRIAAN \& VAN LAAR, 1994; LOOMIS \& AMTHOR, 1999). No entanto, o uso de um valor fixo de UER vem sendo questionado, pois, modelos que contam com um valor fixo de UER, podem ser menos sensíveis a variações nas condições climáticas e no estado fisiológico das plantas (YANG et al., 2004).

Entre as curvas de fotossíntese, a hipérbole retangular tem sido a mais usada em modelagem de culturas, já que, quando utilizada em conjunto com o modelo de interceptação da radiação de Monsi-Saeky, é possível obter soluções analíticas para sua integração no dossel e no tempo (CHAN, 1992). No entanto, em comparação com as outras curvas, suas taxas de fotossíntese são sempre menores em todos os níveis de radiação. Segundo Chan (1992), a curva exponencial negativa apresenta estimativas mais próximas dos dados observados. Entretanto, a curva da hipérbole não retangular, com um parâmetro adicional em relação às curvas exponencial negativa e hipérbole retangular, é mais versátil (THORNLEY \& JOHNSON, 1990). O parâmetro extra " $\theta$ " na hipérbole não retangular faz com que esta curva tenha mais controle na resposta à luz. Em geral, ao observar as curvas de fotossíntese, constatamse três características básicas. A primeira é a inclinação inicial, a segunda é a assíntota e a terceira é a agudez da resposta, isto é, a rapidez com que chega à assíntota. Com os dois primeiros parâmetros, a hipérbole retangular e a exponencial negativa controlam apenas duas destas três características, e a hipérbole não retangular, com o parâmetro extra, controla os três aspectos da curva (THORNLEY \& JOHNSON, 1990).

Quadro 1. Produtividade potencial média do feijão para cada mesorregião, pelos diferentes modelos em kg.ha-1

\begin{tabular}{cccccc}
\hline Mesorregiões & Blackman & $\begin{array}{c}\text { Exponencial } \\
\text { negativa }\end{array}$ & $\begin{array}{c}\text { Hipérbole } \\
\text { retangular }\end{array}$ & $\begin{array}{c}\text { Hipérbole não } \\
\text { retangular }\end{array}$ & $\begin{array}{c}\text { Uso } \\
\text { eficiente } \\
\text { da } \\
\text { radiação }\end{array}$ \\
\hline Zona da Mata & 6000 & 3190 & 2862 & 4019 & 3084 \\
Vale do Jequitinhonha & 6416 & 3597 & 3246 & 4464 & 3475 \\
Triângulo/Alto Paranaíba & 5824 & 3084 & 2768 & 3891 & 3037 \\
Sul/Sudoeste & 6310 & 3476 & 3134 & 4331 & 3214 \\
Campos das Vertentes & 6160 & 3406 & 3083 & 4240 & 3127 \\
Metropolitana & 5859 & 3129 & 2806 & 3944 & 3061 \\
Central Mineira & 5683 & 2970 & 2648 & 3768 & 3036 \\
\hline
\end{tabular}

\section{REVENG}


Quadro 2. Produtividade potencial média do milho para cada mesorregião, pelos diferentes modelos em $\mathrm{kg} \cdot \mathrm{ha}^{-1}$

\begin{tabular}{cccccc}
\hline Mesorregiões & Blackman & $\begin{array}{c}\text { Exponencial } \\
\text { negativa }\end{array}$ & $\begin{array}{c}\text { Hipérbole } \\
\text { retangular }\end{array}$ & $\begin{array}{c}\text { Hipérbole } \\
\text { não } \\
\text { retangular }\end{array}$ & $\begin{array}{c}\text { Uso } \\
\text { eficiente } \\
\text { da } \\
\text { radiação }\end{array}$ \\
\hline Zona da Mata & 17260 & 11029 & 8321 & 11490 & 9656 \\
Vale do Jequitinhonha & 17938 & 11434 & 8607 & 11887 & 10045 \\
Triângulo/Alto Paranaíba & 17076 & 10823 & 8130 & 11267 & 9500 \\
Sul/Sudoeste & 18792 & 11934 & 8994 & 12387 & 10174 \\
Campos das Vertentes & 19581 & 12528 & 9476 & 13035 & 10995 \\
Metropolitana & 17304 & 11076 & 8340 & 11517 & 9688 \\
Central Mineira & 16624 & 10478 & 7837 & 10903 & 9333 \\
\hline
\end{tabular}

Quadro 3. Desvios entre a produtividade potencial média estimada pelos cinco modelos e a produtividade potencial, obtida na literatura para as duas culturas

\begin{tabular}{ccccc}
\hline & \multicolumn{2}{c}{ Feijão } & \multicolumn{2}{c}{ Milho } \\
\hline Modelos & EMBRAPA & $\begin{array}{c}\text { Ministério da } \\
\text { Agricultura }\end{array}$ & UFV & $\begin{array}{c}\text { Ministério da } \\
\text { Agricultura }\end{array}$ \\
\hline Blackman & $51 \%$ & $89 \%$ & $62 \%$ & $109 \%$ \\
Exponencial Negativa & $-18 \%$ & $2 \%$ & $3 \%$ & $33 \%$ \\
Hipérbole Retangular & $-27 \%$ & $8 \%$ & $-22 \%$ & $0 \%$ \\
Hipérbole Não Retangular & $2 \%$ & $28 \%$ & $7 \%$ & $39 \%$ \\
Uso Eficiente da Radiação & $-21 \%$ & $2 \%$ & $-10 \%$ & $17 \%$ \\
\hline
\end{tabular}

\section{CONCLUSÕES}

- A diferença percentual de produtividade potencial entre o modelo de maior e menor estimativa de produtividade foi superior para a cultura do milho, em relação à do feijão;

- A produtividade potencial estimada pelo método de Blackman para as duas culturas foi sempre muito superior enquanto que os demais métodos apresentaram resultados próximos àquelas reportadas na literatura;

- Para a cultura do feijão, a mesorregião Vale do Jequitinhonha apresentou os maiores valores de produtividade potencial média, para todos os modelos, enquanto a mesorregião Central Mineira apresentou os menores. Para a cultura do milho, os maiores valores de produtividade potencial média para todos os modelos foram observados na mesorregião Campos das Vertentes, e os menores, na mesorregião Central Mineira.

\section{REFERÊNCIAS BIBLIOGRÁFICAS}

BRASIL. Ministério da Agricultura. Zoneamento Agrícola de Risco Climático: cultivares de feijão - ano-safra 2006/2007. www.agricultura.gov.br. 17 jun. $2007 \mathrm{a}$.

BRASIL. Ministério da Agricultura. Zoneamento Agrícola de Risco Climático: cultivares de milho - ano-safra 2006/2007. www.agricultura.gov.br. 17 jun. $2007 b$.

CHAN, A.K. Simulation of growth and development of faba bean (Vicia Faba L.) 1992. 217 f. Thesis (Doctor of Philosophy ) Department of Meteorology and Department of Agricultural Botany, University of Reading, Reading, 1992.

${ }^{\circledR}$ CSPL. Model Maker 3 for Windows, version 3.0.2. Cherwell Scientific Publishing, Palo Alto, EUA, 1997. 
EASTERLING, W.E.; MEANS, L.O.; HAYS, C. J.; MARX, D. Comparison of agricultural impacts of climate change calculated from high and low resolution climate change scenarios. Part II. Accounting for adaptation and $\mathrm{CO}_{2}$ direct effects. Climate Change, v.51, p.173-197, 2001.

EMBRAPA - Empresa Brasileira de Pesquisa Agropecuária. Cultivar Pérola. www.cnpaf.embrapa. br/feijao/perola.htm. 15 abr. 2007.

FAO - Food and Agriculture Organization. World agriculture: towards 2015/2030. An FAO Perspective. London: Earthscan Publications LTDA, 2003.

GOUDRIAAN, J.; VAN LAAR, H.H. Modelling potential crop growth processes: The textbook with exercises. Dordrecht: Kluwer, 1994. 239p.

LOOMIS, R. S.; AMTHOR, J.S. Yield potential, plant assimilatory capacity, and metabolic efficiencies. Crop Science, v.39, p.1548-1596, 1999.

MONTEITH, J.L. Climate and the efficiency of crop production in Britain. Philosofical Transactions of the Royal Society, v.281, p.227-294, 1977.

MONSI, M., SAEKI, T. Uber den Lichfaktor in den Pflanzegesellschaften und seine Bedeuttung fur die Stoffpproduktion. Journal of Botany, London, v.14, p.22-52, 1953.
PARRY, M. L.; ROSENZWEIG, C.; IGLESIAS, A.; LIVERMORE, M.; FISCHER, G. Effects of climate change on global food production under SRES emissions and socio-economic scenarios. Global Environmental Change, v.14, p.53-67, 2004.

PENNING DE VRIES, F.T.W. The cost of maintenance processes in plant cells. Annals of Botany. Wageningen, v.39, p.77-92, 1975.

THORNLEY, J.H.M.; JOHNSON, I. R. Plant and crop modelling: A mathematical approach to plant and crop physiology. New York: Oxford University Press, 1990. 669p.

TOJO SOLER, C.M. Uso do modelo Ceres-Maize para previsão de safra do milho "safrinha". 2004. $146 \mathrm{f}$. Tese (Doutorado em Agronomia) - Escola Superior de Agricultura Luiz de Queiroz, Piracicaba, 2004.

YANG, H.S.; DOBERMANN, A.; LINDQUIST, J.L.; WALTERS, D.T.; ARKEBAUER, T.J.; CASSMAN, K.G. Hybrid-maize - a maize simulation model that combines two crop modeling approaches. Field Crops Research, v.87, p.131154, 2004.

WOLSCHICK, D. Modelo SIMASS-C: inclusão da modelagem do crescimento e desenvolvimento do milho. 2004. 140f. Tese (Doutorado em Engenharia Agrícola) - Universidade Federal de Viçosa, Viçosa, 2004. 